\title{
Vowel Epenthesis in Toda Songs
}

\author{
Aliaa Aloufi \\ Community College, Taibah University, Medina, Saudi Arabia
}

Received November 8, 2020; Revised December 17, 2020; Accepted January 20, 2021

\begin{abstract}
Cite This Paper in the following Citation Styles
(a): [1] Aliaa Aloufi, "Vowel Epenthesis in Toda Songs," Linguistics and Literature Studies, Vol. 9, No. 1, pp. 22 - 26, 2021. DOI: 10.13189/lls.2021.090103.
\end{abstract}

(b): Aliaa Aloufi (2021). Vowel Epenthesis in Toda Songs. Linguistics and Literature Studies, 9(1), 22 - 26. DOI: 10.13189/lls.2021.090103.

Copyright $\odot 2021$ by authors, all rights reserved. Authors agree that this article remains permanently open access under the terms of the Creative Commons Attribution License 4.0 International License

\begin{abstract}
This study looks at a minor but interesting phonological phenomenon that is vowel epenthesis in Toda songs, a Dravidian language spoken in South India. The purpose of this paper is to elaborate the extent to which vowel epenthesis is used to satisfy the poetic meter preferences in songs and verses that are sensitive to the number of syllables per line in the light of Optimality Theory (OT). This study was largely based on songs collected by Emeneau [1] and recently recognised by Fabb [2]. It offers an analysis of vowel epenthesis using the ranked and violable constraints of OT [3]. The conclusion of the paper is that vowel epenthesis is triggered by a non-rhythmic size meter that constrains the length of the line of the poetic form in Toda to be strictly three syllables [4]. Within OT, violation and the strict domination of OT constraints are capable of accounting for the vowel epenthesis in Toda songs. Theoretical insights from OT enrich our understanding not only of Toda phonology but also of its metric rules. More generally, OT is shown in this study to be a framework which manages to give meaningful clarification of complex and specific literary-linguistic interaction patterns found in a given language.
\end{abstract}

Keywords Toda, Vowel Epenthesis, Optimality Theory

\section{Introduction}

Epenthesis refers to the insertion of a segment into a word in a position in which no segment was formerly present [5]. This additional segment can be vowel or a consonant that is normally inserted into the word internally. The epenthesis of segments is a common phonological process used to satisfy constraints on phonotactics and syllable structure in a given language, which can be perhaps as a result of hiatus (separating two vowels) or consonant clusters (separating two consonants). Vowel epenthesis besides it is an attempt to preserve more acceptable phonotactics in a language and it is a rarely observed phenomenon in songs as it can be used as a poetic device to achieve the meter requirement in verse. The English song 'The Umbrella Man' is an illustration of this phenomenon, where the meter requires the word 'umbrella' to be four syllables, um-buh-rel-la, consequently 'any umbrellas' has the meter ány úmberéllas [6]. This similarly occurs in Toda songs, where the required syllable is three [1]. This specific literary-linguistic interaction is the focus of this study.

Toda songs constitute a very interesting area for questions about specific literary-linguistic rules in relation to the phonological rule of the language. This study aims to investigate vowel epenthesis in Toda songs under an Optimality Theory (OT)-based poetic meter rather than prose-based constraints; despite the claimed distinctions between the two systems, the formalism still remains the same. To achieve this aim, two questions are addressed. The first is the extent to which extant vowel epenthesis plays a role in fulfilling the poetic meter requirements in Toda songs, while the second investigates how to account for vowel epenthesis in Toda songs using OT. The next section provides a basic theoretical background regarding poetic meter, after which is a section looking at essential issues regarding Toda language and its songs that are relevant to this research. The fourth section presents the grammar of vowel epenthesis in Toda songs through a unified set of OT constraints, while the conclusion, presented in the final section, provides a summary of the study and its findings. 


\section{Literature Review}

The application of linguistic theory to literature is generally known as 'literary linguistics' and fundamentally explores how linguistic theory relates to the special characteristics of literary texts [7]. In literary texts, more specifically songs, it is essential to consider the complex relations between metrical and phonological form. Several linguistically sensitive metrical researches have notably considered how literary and linguistic rules operate and interact [7]. It is essential to consider this relation between metrical form and linguistic form; the question here is which aspects of linguistic form are controlled by which aspects of metrical form? In any metrical text, the phonological constituents are governed by metrical rules [7]. Two aspects of phonological form are considered: phonological constituency, and (in some cases of rhythmic meters) phonological prominence. Meter might account for any kind of phonological constituents, as in the French alexandrine, where it is the syllables that meter counts (12 syllables in a line). This implies that the musical text might be organised by a syllable-counting meter derived from metrical texts.

As far as literary text is concerned, the earliest approaches of linguistic metrics see rhythm as the defining property of meter, adhering to the significant role of meter in linguistic theories, in which most verse systems known to linguists contain an alternating pattern of strong and weak syllables (Halle and Keyser [8,9], Fabb and Halle [10]). Still, there are poetic forms

$\begin{array}{ll}\text { pet-fu:f-o:j } & \text { pu:tǔur } \\ \text { Cane-flower-becoming } & \text { if you blossom } \\ \text { kat-fu:f-o:j } & , \\ \text { Strobilanthes-flower-becoming } & ,\end{array}$

cross-linguistically that somewhat fix the phonological form of the text, for instance by constraining the length of lines without creating rhythm [4]. These non-rhythmic genres require the poetic forms to conform to an abstract prosodic template as they either constrain the size and prominence or constrain the size and ignore the prominence at different levels of the prosodic hierarchy [4]. Furthermore, non-rhythmic meters support the fundamental fact of generative metrics that general phonology and meter come from a common source [4]. Building on this perspective, this study will assume that the meter in Toda songs is a non-rhythmic one.

\section{Toda Songs and Epenthesis}

The songs of Toda, a Dravidian language of the Nilgiri plateau in South India, are a corpus of 260 texts that has been primarily collected to undertake a stylistic analysis by Emeneau [1,11]. This Dravidian language is known for its numerous trills and fricatives and originated from Tamil-Kannada [12]. The art of song among the Todas (a population of one thousand people) is highly developed and plays an essential role in their life as it is based on legendary stories [11]. The following is a wonderful sequence taken from a song that shows unique constitutions of the song where the suiter compares himself to the bee and his loved to a flower (Emeneau [11]:551):

$\begin{array}{ll}\text { pe(t)-t0:n-o:j } & \text { kǔusa } \theta \text { eng } \\ \text { cane-bee-becoming } & \text { I have sucked } \\ \text { k- } \theta \text { ö:n-o:j } & , \\ \text { Black-bee-becoming } & ,\end{array}$


In these songs, Emeneau [1] has noted that most of the song constituents contain two monosyllabic words that are fundamentally lengthened in order to achieve the required length of three syllables and satisfy the para-metrical rules that are, in this case, regulated by the sound-patterning rules. This is applied through several procedures, either by the resyllabification of long vowels into two vowels of the same quality, in which one is short and the other is long, or by the epenthesis of vowels [1] (which is considered here).

In Toda songs, the epenthetic vowel is inserted in order to create additional syllable to fulfil the para-metrical requirement. The epenthesis of [i] normally precedes a suffix ('on' or 'in') that expresses location in the first of the two monosyllabic words. Consider the following lines taken from the song (Emeneau [1]:326):

\begin{tabular}{|c|c|c|}
\hline 1. & $\operatorname{morjif} \operatorname{mox}$ & 'on-the-lap child' \\
\hline 2. & nitjif xo's & 'on-the-forehead coin' \\
\hline 3. & karis xor & 'in the calf pen calf' \\
\hline 4. & ko'lis xag & 'on the feet black-yarn' \\
\hline 5. & puti $\theta$ fuf & $\begin{array}{l}\text { 'a flower which has } \\
\text { blossomed' }\end{array}$ \\
\hline 6. & talis nir & 'on the head water' \\
\hline 7 & madis ni'r & 'on-the- head water' \\
\hline & no'tis $\theta o^{\prime} r$ & 'in-the-places important men' \\
\hline
\end{tabular}

Apparently, this suffix is under-specified, as it shares some of its features from the preceding consonant. For instance, the suffix in line (1) and (2) is the palatal consonant [ $]$ ], so it is preceded by the palatal glide [j], while in lines (7) and (8), the suffix is the alveolar consonant [s], preceded by the alveolar consonants [d] and [t], respectively (Fabb 1997). However, it should be noted that in the Toda language, the suffix is normally the voiced consonant $[\mathrm{z}]$ if the preceding sound is the voiced vowel [i], which indicates that the insertion occurred after the specification of the suffix feature [2]. Crucially, dealing with songs and poetry is distinctly different from prose, as poetry commonly refers to the artistic discourse that is divided into lines and the internal organisation of lines is governed by linguistic factors such as meter, parallelism or both (Fabb and Halle [10]:1, Hanson and Kiparsky [13]:289).

\section{Optimality-Theoretical Analysis}

The choice of theoretical framework that is capable of investigating the occurrence of insertions in Toda songs is based on certain criteria. Given that this study seeks to model complexity with simple elements, it adopts a constraint-based theory, founded in OT [3]. The OT research literature has a strong record that is capable of dealing with complex data via simple constraints with crucial forms of prioritisation or ranking in order to regulate the conflicting constraints. In light of the OT framework, this analysis is started by the assumption that the meter in Toda songs is non-rhythmic pure size meter that constrains the line containing a fixed number of syllables [14]. This meter constrains the size of the line and neglects the size of any prosodic constituent below the line. Since this meter does not have any constituents resembling poetic feet, this suggests that the analysis must treat the line as a metrical primitive. Possible typology for size meter can be modelled depending on the three parameters of Hanson and Kiparsky [13] in their account for periodic meter, the poetic molecule (which prosodic constituent is constrained for size), the poetic atom (which constituents are counted) and the number of molecules per minimal poetic constituent (line or text). The assumption here is that possible poetic molecules and atoms may contain all of the levels of the prosodic hierarchy, mora < syllable < foot < word, followed by three poetry-specific constituents dominating the word: sub-linear constituents such as < line < text. Building on this assumption, this analysis argues that the Toda song meter constrains the size of the prosodic words in terms of numbers of syllables (atoms), but does not constrain the number of prosodic words (molecules) per line. OT grammar is used to metrically derive constraints via markedness which then combined with faithfulness constraints, enforcing faithfulness to the lexical form of the text, not to the meter, to derive meter [4]. The size molecule parameter given in (1) determines which constituent of the poetic prosodic hierarchy is constrained for size; the size atom parameter, and which constituent is used to measure the size molecule (Skilton [4]:34):

MinMolecule: Assign one violation for every SIZE ATOM by which the SIZE MOLECULE falls short of $n$ SIZE ATOMS.

MaxMolecule: Assign one violation for every SIZE ATOM by which the SIZE MOLECULE exceeds $n$ SIZE ATOMS.

The MinMolecule and MaxMolecule constraints will be used to formalise size requirements in Toda songs that regulate the size of the line and set the same target for every line of the songs using the following markedness constraints MinLine and MaxLine illustrated as follows:

MinLine: Assign one violation for every syllable by which the line falls short of three syllables.

MaxLine: Assign one violation for every syllable by which the line exceeds three syllables.

Along with these constraints, further markedness constraints are needed in relation to a phonological stratum that operates on the output of the poetry-specific phonological processes, beginning with the syllable structure constraint that is *COMPLEX (Prine and Smolensky [3]:85), which indicates that syllables have at most one consonant at an edge, as well as RMORPH [15] which ensures the locative suffix surfaces in the songs:

*COMPLEX: No more than one $\mathrm{C}$ or $\mathrm{V}$ may associate 
to any syllable position node.

RMORPH: A morpheme must be phonologically realized in the output.

When a vowel is inserted in the output without its counterpart in the input, the inserted segment is only determined by markedness factors. Accounting for the epenthesis and process employed in Toda song, two constraints are used in this analysis to control the insertion of the vowel; the correspondence faithfulness constraint DEP-IO is required (McCarthy and Prine [16]: 262):

DEP-IO: every segment of the output has a correspondence in the input (no epenthesis)

Even though this constraint is violated in default vowel insertion, nevertheless violation is minimal as a segment will be inserted though it is counterbalanced by a markedness constraint that bans feature sharing. It clearly requires that every feature is associated with only one segment, that is the *MULTIPLE constraint adopted from Uffmann ([17,18]):

*MULTIPLE: features are associated with one mother node only (no spreading)

This constraint is capable of stopping VI from being harmonic with V2 and, consequently, with the absence of any identity between VI and V2, the default vowel emerges. Accordingly, this constraint has two functions of blocking harmony and allowing the occurrence [i]. The nature of *MULTIPLE constraint means that it is in conflict with the faithfulness constraint $\mathbf{D E P}(\mathbf{I O})$ which militates against insertion of segment that has no correspondent in the input. Vowel insertion will always lead to the violation of one of the $\mathbf{D E P}(\mathbf{I O})$. This conflict can be managed by ranking the two constraints with respect to each other: *MULTIPLE » DEP(IO) in order to trigger the default vowel insertion. Concerning the ranking of other constraints, MinLine and MaxLine are unviolated. Both markedness constraints are equally ranked above other constraints in the evaluation. *COMPLEX and RMORPH are also never violated to ensure the preferred position of the epenthatic vowel. The violation of DEP-IO is allowed in the service of creating new syllables by enabling the epenthesis of vowels. This led to the crucial constraint ranking in (1):

\section{(1) Ranking of constraints}

\section{MinLine, MaxLine >> RMORPH $>$ > COMPLEX >> *MULTIPLE $\gg *$ DEP-IO}

Candidates (a) without the locative suffix fatally violate RMorph, alongside the violations of MinLine (two syllables instead of three) and *COMPLEX (coda cluster [rj]). Candidate (b) violates MinLine as it is shorter than the required line meter (only two syllables), alongside the fatal violation of * COMPLEX, with its complex coda [j $\left.\int\right]$. Candidate (d) has two violations *MULTIPLE as it has vowel harmony as well as Dep-IO. Candidate (c) is the optimal output, even though it only violates Dep-IO with its epenthesised vowel, hence it is considered the lowest in the rank. With such basic ranking of markedness and faithfulness constraints, it can precisely predict the epenthesis of vowel in Toda songs that is triggered by the syllable-counting meter.

Table 1. Optimality-theoretic selection of output for vowel epenthesis in Toda songs

\begin{tabular}{|c|c|c|c|c|c|c|}
\hline & MaxLine & MinLine & RMorph & *COMPLEX & $*$ MULTIPLE & Dep-IO \\
\hline (a) morj mox & & $*$ & $* !$ & $*$ & & \\
\hline (b) morjf mox & & $*$ & & $* !$ & & $*$ \\
\hline$\rightarrow$ (c) morjif mox & & & & & $*$ & $*$ \\
\hline (d) morjof mox & & & & & $*$ \\
\hline
\end{tabular}




\section{Conclusions}

This paper has mainly focused on linguistics, more precisely phonology, as well as the poetic properties of one genre of song poetry in the Toda language. In summary, a unified set of meter-based constraints along with phonological-based ones account for the epenthesis of vowels in Toda songs. It also reveals how OT as a framework can go beyond phonological patterns and tackling unique literary-linguistic issues, where a generated non-rhythmic meter that constrains the size of the line mandates the vowel epenthesis in Toda songs. To further define the literary-linguistic interactions, future research could implement the OT analysis by including constraints specific to the type of phonological processes as well as the poetic systems involved in a language.

\section{Acknowledgements}

This research has been generously supported and funded by the Research Centre at Taibah University.

\section{REFERENCES}

[1] M. B. Emeneau. Style and Meaning in an Oral Literature, Language, Vol. 42, No. 2, 323-45, 1966.

[2] N. Fabb. Linguistics and Literature: Language in The Verbal Arts of The World, Blackwell, Oxford, 1997.

[3] A. Prince, P. Smolensky. Optimality Theory: Constraint Interaction in Generative Grammar. Technical report, Rutgers University Center for Cognitive Science, Blackwell, Oxford, 1993/2004.

[4] A. Skilton. Meter without Feet, 2016. Available online at http://www.linguistics.berkeley.edu/ amaliaskilton/skilton_ phdqp_meter-without-feet_revised_20161214.pdf. Accessed October, 2020.
[5] R. L. Trask. A Dictionary of Phonetics and Phonology, Routledge, London, 2004.

[6] A. Iyiola. Autosegmental Representation of Epenthesis in the Spoken French of Ijebu Undergraduate French Learners in Selected Universities in South-West of Nigeria. African Research Review, An International Multidisciplinary Journal, Ethiopia, Vol. 9(4), No. 39, 123-138, 2015.

[7] N. Fabb. Linguistics and literature, Blackwell Handbook of Linguistics Handbooks in Linguistics, Wiley-Blackwell, Oxford, 2016.

[8] M. Morris, S. J. Keyser. Chaucer and the study of prosody, College English, Vol. 28, No. 3, 187-219, 1966.

[9] M. Morris, S. J. Keyser. English Stress: its form, its growth, and its role in verse, Harper and Row, 1971.

[10] N. Fabb, M. Halle. Meter in poetry: A New Theory. Cambridge University Press, Cambridge, 2008.

[11] M. B. Emeneau. The Songs of Todas, Proceedings of the American Philosophical Society Vol. 77, No 4, 543-560, 1937.

[12] B. Krishnamurti, The Dravidian Languages, Cambridge University Press, Cambridge, 2003.

[13] K. Hanson, P. Kiparsky. A Parametric Theory of Poetic Meter, Language, Vol. 72, No. 2,287-335, 1996.

[14] A. Rumsey. A Metrical System That Defies Description by Ordinary Means. A Journey Through Austronesian and Papuan, Linguistic and Cultural Space, Canberra, Pacific Linguistics, 39-56, 2010.

[15] V. Same-Lodovici. A Unified Analysis of Crosslinguistic Morphological Gemenation, Precedings of CONSOLE I, 265-283, 1993.

[16] J. McCarthy, A. Prince. Faithfulness and Reproductive Identity, Papers in Optimality Theory, University of Massachusetts Occasional Papers 18, Amherst GLSA, 249-384, 1995.

[17] C. Uffmann. Patterns of Vowel Epenthesis (not only) in Shona Loanwords, Proceedings of HILP 5, Universität Potsdam, 193-211, 2001.

[18] C. Uffmann. Optimal Geometries, The Internal Organization of Phonological Segments, de Gruyter, Berlin, 27-62, 2005. 